\title{
IMPACT OF ACTIVATORS OF ORGANIC MATTER ON SOIL AND CROP STAND PROPERTIES IN CONDITIONS OF VERY HEAVY SOILS
}

\author{
Petr Sarec, Petr Novak, Jitka Kumhalova \\ Czech University of Life Sciences Prague \\ psarec@tf.czu.cz
}

\begin{abstract}
Agricultural land in the Czech Republic is characterized by a high proportion of arable land. The current land management is characterized by a loss of livestock and biofuel production. This leads to a decrease in the level of soil carbon in the soil. Decrease in organic carbon levels also leads to easier soil degradation by other factors (erosion, compaction). Application of large amounts of organic matter into soils is the only remedy. Decomposition of organic matter may be problematical in the decarburized soils. Therefore, organic matter can be supplemented by biological transformation activators. The aim of this paper is to demonstrate the efficacy of activators of organic matter in improving the soil environment. Field experiment was established at locality Sloveč in the Central Bohemia Region. Very heavy soil is located on the experimental plot. Results of the six variants with cattle manure are presented in this paper. The soil activator used was PRP Sol (PRP Technologies). The activator of the biological transformation of manure was PRP Fix (PRP Technologies). Favourable effect on the bulk density and other physical soil properties could be observed during the measurement of the physical properties of soil. Vegetation indices were another consideration for rating. They suggest a beneficial effect of application of bio-activators.
\end{abstract}

Keywords: activator of organic matter, manure application, soil properties, vegetation indices.

\section{Introduction}

During the past years, agriculture has suffered a decrease in livestock production in the Czech Republic. This also meant a decline in production of organic fertilizers. Lately, the situation may be changed in connection with the subsidy policy and the emphasis on the sustainability of agricultural production with respect to soil protection [1]. Low levels of soil carbon leads to a decrease in fertility. In addition, decarburized soil is not able to degrade the organic matter due to the decreased microbial activity [2]. Soil activity is necessary to restore using enzymes and activators [3]. Application of organic matter together with activators should result in improved physical properties of soil [1]. One of the methods of evaluating the impact of the application of organic material and of activators is also through vegetation indices. Indices may testify about the state of plants on the field in terms of the soil condition, water-supply conditions and other aspects [4]. Vegetation indices can be created by utilizing the data from satellites. Use of satellite images is a rapidly developing area with high impact on the current farming.

The Sentinel-2 satellites provide imagery for the generation of high-level operational products. Data from Sentinel-2 benefit services, for example, in areas such as land management or agricultural industry and forestry [5]. Multispectral Sentinel-2 imagery also allows us to derive many indices that can be used for explaining plant variability. Spectral vegetation indices are mathematical combinations of different spectral bands that lie mostly in the visible and near infra-red regions of the electromagnetic spectrum [6]. The most widely used index mentioned in the literature is the Normalised Difference Vegetation Index (NDVI) [7]. Input premise of the study is to improve the physical properties of the soil and to improve the plant growth conditions based on the application of farmyard manure and activators.

\section{Materials and methods}

The field experiment was founded in locality Sloveč in the Central Bohemia Region. A field trial was established to demonstrate the influence of the activators of organic matter on soil and crop stand properties. The establishment of the experiment occurred in 2014. A field trial was divided into 6 basic variants. The topography is a plane, altitude is $214 \mathrm{~m}$ above the sea level. The soil type in the location Sloveč is heavy black soil. The content of particles $<0.01 \mathrm{~mm}$ is $38 \%$, weight (depth $0-0.3 \mathrm{~m}$ ). The experiment plot was divided in 2014 into individual variants where fertilizer application was carried out according to a plan and autumn soil tillage by tines to a depth of $0.25 \mathrm{~m}$ was implemented. The fertilizers used were farmyard manure (breeding cattle), and NPK 15-15-15 (Lovofert). The soil activator used in the experiment was PRP Sol (PRP Technologies, France). PRP Sol is formed by a 
basic matrix of calcium and magnesium carbonate, and mineral elements. The activator of the biological transformation of manure was PRP Fix (PRP Technologies, France). PRP Fix is a granular mixture of mineral salts and carbonates. Activators cannot be understood as fertilizers. They operate as excipients, and should improve conditions for transformation of organic matter. The variants differed only by the fertilizers and activators used. Dosage of farmyard manure was $50 \mathrm{t} \cdot \mathrm{ha}^{-1}$, of PRP Sol $200 \mathrm{~kg} \cdot \mathrm{ha}^{-1}$, of NPK $200 \mathrm{~kg} \cdot \mathrm{ha}^{-1}$. PRP Fix activator was added directly into the bedding (directly in cowshed). Description of individual variants is shown in Table 1.

Table 1

\section{Fertilization of individual variants of field experiment}

\begin{tabular}{|c|c|}
\hline Variant & Fertilization \\
\hline 1 & Manure+Fix+NPK \\
\hline 2 & Manure+Fix+Sol+NPK \\
\hline 3 & Manure+NPK \\
\hline 4 & Manure+Sol+NPK \\
\hline 5 & NPK+Sol \\
\hline 6 & NPK - control \\
\hline
\end{tabular}

The soil was prepared by a seedbed combinator during the spring of 2016. Barley was sown on all variants. In May 2016 after germination of barley, measurements of the soil properties were taken (after BBCH 10). The data were subsequently analyzed with utilization of software Microsoft Excel (MS Corp., USA) and Statistica 12 (Statsoft Inc., USA).

Sentinel 2A images were obtained from the Amazon Web Services (http://sentinel-pds.s3website.eu-central-1.amazonaws.com/). All cloud-free images (see Table 2) available over the study area from the years 2016 between April and June have been selected. ENVI 5.4 (Excelis, Inc., McLean, USA) remote sensing software was used for processing all the images.

Table 2

Available Sentinel 2 images for the selected year

\begin{tabular}{|c|c|c|c|}
\hline Crop & Date & Sensor & Satelitte \\
\hline Barley & $\begin{array}{c}\text { 29-Apr-2016, 6-May-2016, 8-June-2016, } \\
\text { 25-June-2016 }\end{array}$ & MSI & Sentinel 2A \\
\hline
\end{tabular}

The images were processed in Level-1C format only. This format is an orthorectified product providing Top of Atmosphere (TOA) Reflectance. Selected spectral indices (see Table 3) were calculated.

Table 3

Spectral indices evaluated in this study

\begin{tabular}{|c|c|c|}
\hline Spectral Index & Algorithm & References \\
\hline $\begin{array}{c}\text { Normalized Difference } \\
\text { Vegetation Index (NDVI) }\end{array}$ & (NIR - RED) / (NIR + RED) & Rouse et al. [8] \\
\hline Moisture Stress Index (MSI) & SWIR1 / NIR & Rock et al. [9] \\
\hline
\end{tabular}

Total monthly precipitation and temperature data were provided by the Agro meteorology station in Sloveč. Precipitation and temperature for the observed years are also stated in Table 4.

Table 4

Precipitation and temperatures at different growth stages by BBCH scale recorded in the experimental field for barley in 2016

\begin{tabular}{|c|c|c|}
\hline Year 2016 & Precipitation, $\mathbf{~ m m}$ & Temperature, $^{\mathbf{}} \mathbf{C}$ \\
\hline BBCH 0-29 & 68 & 6.8 \\
\hline BBCH 30-59 & 133 & 16.8 \\
\hline After BBCH 60 & 110 & 18.8 \\
\hline Sum & 311 & - \\
\hline Mean & 103.7 & 14.1 \\
\hline
\end{tabular}




\section{Results and discussion}

Figure 1 is a graph of bulk density values for all the variants. Visible differences exist between the variants. The data were processed using the Tukey HSD test. Statistically significant difference exists only between Variant 2 and Variants 3, 4, 6 and furthermore between Variant 6 and Variants 1, 2, 3, 5. Nevertheless, the trend indicates a favorable impact of applications of organic matter and activators. Variant 6 (without the application of manure and activators) showed the highest values of soil bulk density. This demonstrates the positive effect of the application. The lowest value of bulk density of Variant 2 indicates a beneficial effect of the activators on the decomposition of organic material (manure) in the soil, and an overall improvement of the physical soil properties.

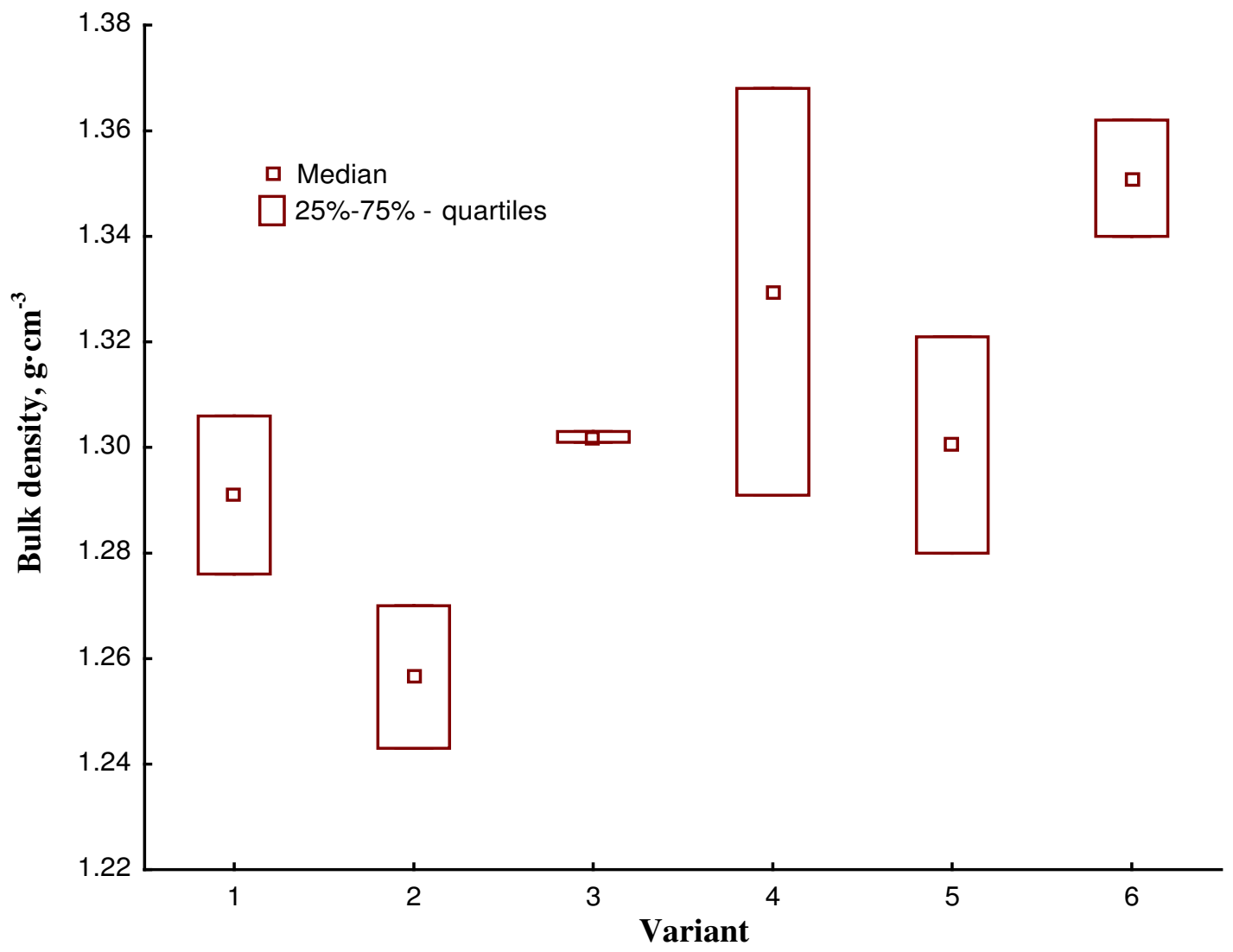

Fig. 1. Bulk density for all variants in Sloveč in $\mathbf{2 0 1 6}$

Figure 2 shows the NDVI index for all variants in 4 terms. During the major growth phases (BBCH 10-50), the crop stand shows higher values of the NDVI index in variants with manure and activators. The highest values were observed in Variant 2. During the later stages of vegetation (after $\mathrm{BBCH}$ 51), the situation was not clear. The highest index values were recorded during the measurement from June 8, 2016. This could be due to the change of reflectivity during heading. The difference in the values among the variants is not major. But the trend indicates better physiological condition of plants of the variants wherein the organic material has been applied along with the activators. Different fertilization also may have caused a slight shift of the vegetation phases among the variants. This is particularly apparent within the measurement from June 8, 2016. The NDVI index values are significantly influenced by the chlorophyll content.

The measurement from June 25, 2016 cannot be interpreted unambiguously. During the flowering phase and after it occurs at cereals, physiological changes and vegetation indices may vary considerably due to the changes in the color of vegetation and a decrease in the chlorophyll content [4]. From the values of NDVI, a beneficial effect of activators linked to an increase in microbial activity in the soil, and to more prosperity for plants on individual plots, may be expected.

Figure 3 shows the MSI index for all variants in 4 terms. In three cases, the positive effect of the application of manure and activators can be discerned. The MSI index reflects the degree of stress of plants in terms of their water-supply. 

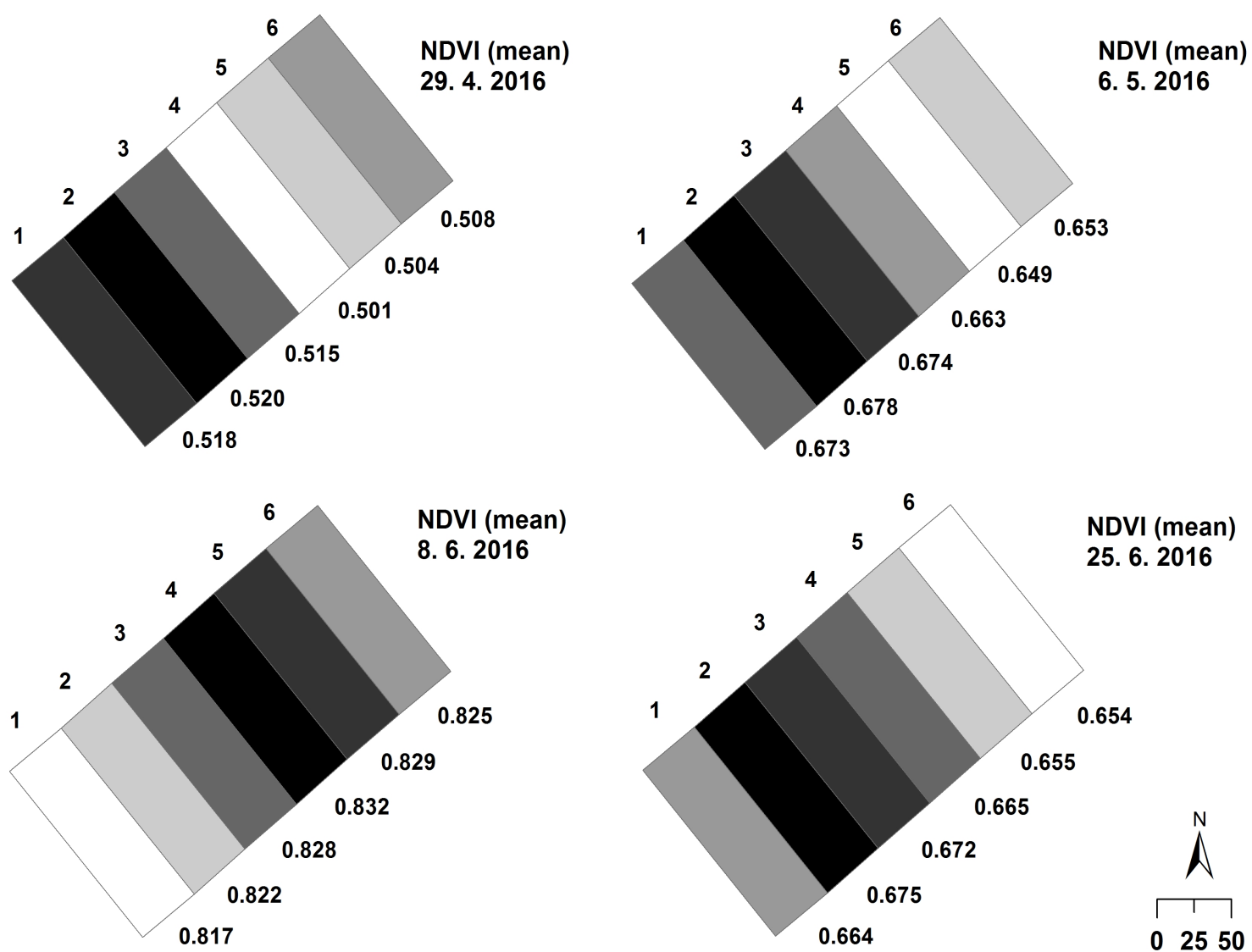

NDVI (mean)

25. 6. 2016

.654

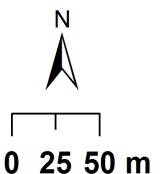

Fig. 2. NDVI index for all variants in Sloveč
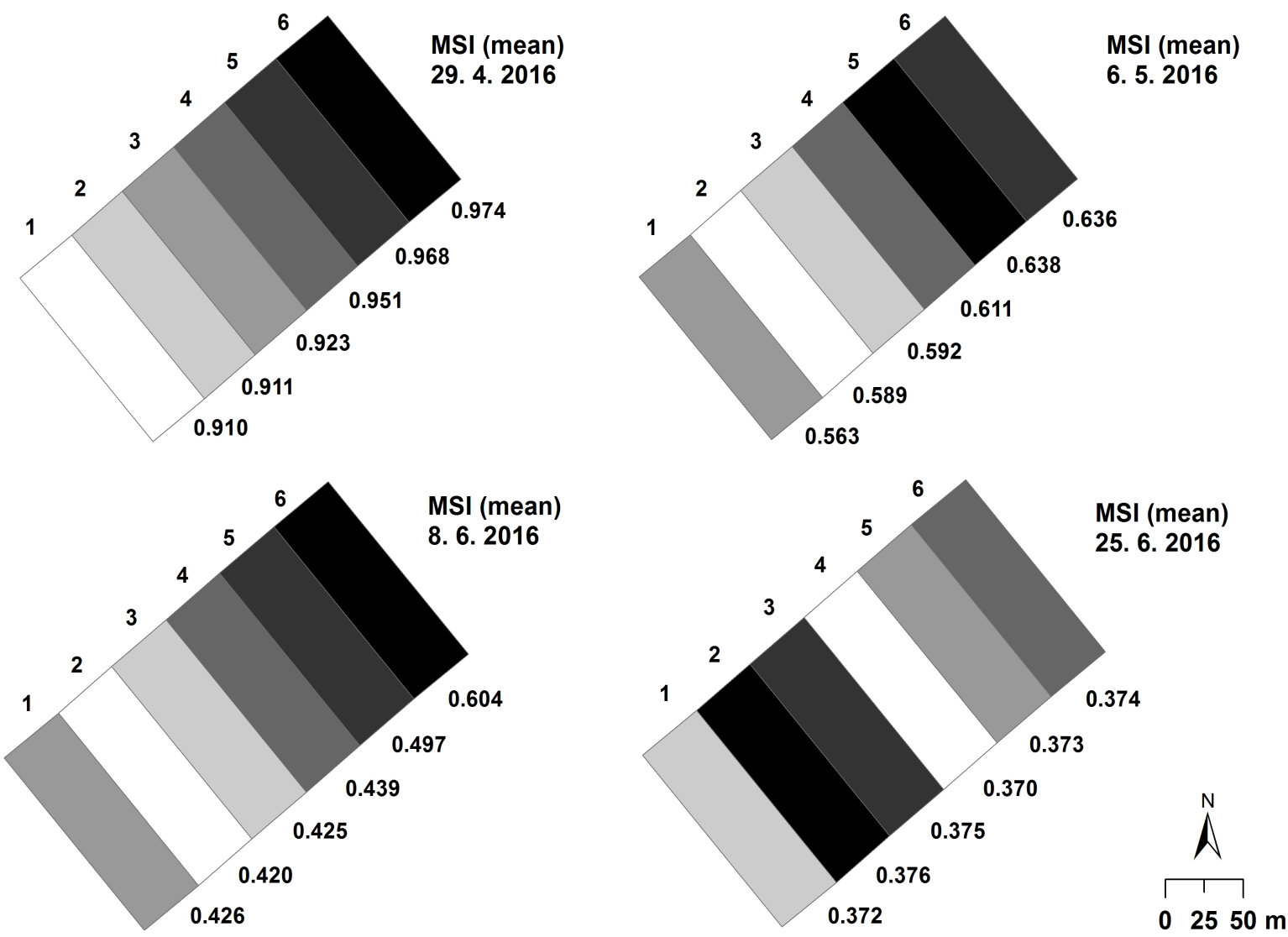

Fig. 3. MSI index for all variants in Sloveč 
The MSI index therefore clearly demonstrates the effect of manure application with activators. Only on June 25, 2016, the effect was not confirmed, but the index values may have been again affected by the change of color of vegetation during the advanced stages of vegetation. The values in the vegetative stage $\mathrm{BBCH}$ 20-50 demonstrated a beneficial effect of manure application with activators on water supply of plans. This was probably caused due to an increase in soil porosity. This is confirmed by the decline in values of soil bulk density (see Fig. 1). This results in a higher capillarity of soil water. Plants are better supplied by ground water during drought. Absolute differences among the variants are relatively small. Overall, this phenomenon needs a long-term research on multiple locations with different soil conditions. From the values of the MSI, a beneficial effect of activators on the decomposition of organic matter in soil may be expected, which may result to an improved capillarity of soil water.

Similar studies were often targeted for soil properties. Hůla and Kovaříček [10] found the beneficial effect of organic matter on soil properties (decrease bulk density and increase porosity). This was confirmed by other authors [2;3]. During this study, a positive effect on the management of soil moisture was observed. This was probably caused due to a higher porosity of soil. Higher porosity should also lead to a higher rate of water infiltration into the soil. Application of organic matter together with activators resulted in higher water infiltration into the soil [1]. This phenomenon corresponds with the MSI index values in this study. Overall, the application of soil activators and of activators of organic matter constitutes a relatively new problem that merits further research in many aspects.

\section{Conclusions}

The research results showed that:

1. Application of organic matter and activators resulted in improvement of the physical properties of soil, especially decrease of the bulk density.

2. Application leads to improvement in water-supply of plants during the period of dryness situations. This is confirmed by the MSI index values of individual variants.

3. Application resulted in improvement of the physiological state of plants, which was reflected in an increased NDVI index.

4. This research results are not entirely clear and need long-term verification with more types of crops with different root systems.

5. Research must be carried out at various locations with different soil conditions.

\section{Acknowledgements}

This work was supported by Research Project of the Technology Agency of the Czech Republic no. TH02030169.

\section{References}

1. Šařec P., Novák P. Influence of biological transformation of organic matter on improvement of water infiltration ability of modal luvisol. In 6th International Conference on Trends in Agricultural Engineering (TAE) 07.09.2016, Czech Univ Life Sci, Fac Engn, Prague, Czech republic, pp. 627-632.

2. Anderson T.H, Domsch K.H. Ratio of microbial biomass carbon to total organic carbon in arable soils. Soil Biology \& Biochemistry, vol. 21,1989, pp. 471-479.

3. Nannipieri P. The potential use of soil enzymes as indicators of productivity, sustainability and pollution. C.E Pankhurst (Ed.), Soil Biota. Management in Sustainable Farming Systems, CSIRO, East Melbourne, Victoria, Australia, 1994, pp. 238-244.

4. Domínguez J.A., Kumhálová J., Novák P. Winter oilseed rape and winter wheat growth prediction using remote sensing methods. Plant, Soil and Environment, vol. 61, no. 9, 2015, pp. 410-416.

5. Julien Y., Sobrino J.A., Jiménez-Muñoz J.C. Land use classification from multitemporal Landsat imagery using the Yearly Land Cover Dynamics (YLCD) method. International Journal of Applied Earth Observation and Geoinformation, vol. 13, 2011, pp. 711-720.

6. Baillarin S.J., Meygret A., Dechoz C. Petrucci B., Lacherade S., Tremas T., Isola C., Martimort P., Spoto F. 2012. Sentinel-2 level 1 products and image processing performances. International 
Archives of the Photogrammetry, Remote Sensing and Spatial Information Sciences, vol. XXXIX-B1, XXII ISPRS Congress, 25 August - 01 September 2012, Melbourne, Australia, pp. 197-202.

7. Viña A., Gitelson A.A., Nguy-Robertson A.L., Peng Y. Comparison of different vegetation indices for the remote assessment of green leaf area index of crops. Remote Sensing of Environment, vol. 115, 2011, pp. 3468-3478.

8. Rock B.N., Williams D.L., Vogelmann J.E. Field and airborne spectral characterization of suspected acid deposition damage in red spruce (Picea rubens) from Vermont. In Proceedings Symposia on Machine Processing of Remotely Sensed Data, Purdue University, West Lafayette, IN., 1985, pp. 71-81.

9. Rouse J., Haas R., Schell J.A., Deering D. Monitoring vegetation systems in the Great Plains with ERTS. In Proceedings Third ERTS-1 Symposium, NASA Goddard, NASA SP- 351, 1974, pp. 309-317.

10. Hůla J. , Kovaříček P. Water infiltration into soil and surface water runoff in maize growing by three cultivation technologies. In: Trends in Agricultural Engineering. Czech University of Life Sciences Prague, 2010, pp. 232-235. 